\title{
Characterization of soil particles by X-ray diffraction (XRD), X-ray photoelectron spectroscopy (XPS), electron paramagnetic resonance (EPR) and transmission electron microscopy (TEM)
}

\author{
Karine FlogeaCa, Emmanuel GuILlon ${ }^{a *}$, Michel APlinCOURT ${ }^{\mathrm{a}}$, Eric MARCEAU ${ }^{\mathrm{b}}$, Lorenzo STIEVANO ${ }^{\mathrm{b}}$, \\ Patricia BEAUNIER ${ }^{\mathrm{b}}$, Yves-Michel FRAPART ${ }^{\mathrm{c}}$
}

\footnotetext{
${ }^{a}$ GRECI (Groupe de Recherche En Chimie Inorganique), Université de Reims Champagne-Ardenne, BP 1039, 51687 Reims Cedex 2, France

${ }^{\text {b }}$ Laboratoire de Réactivité de Surface, Université Pierre et Marie Curie, UMR CNRS 7609, 4 place Jussieu, 75252 Paris Cedex 05, France

${ }^{\mathrm{c}}$ Laboratoire de Chimie et Biochimie Pharmacologiques et Toxicologiques, UMR CNRS 8601, IFR 95, Université René Descartes, 45 rue des Saints Pères, 75270 Paris Cedex 06, France
}

(Accepted 16 February 2005)

\begin{abstract}
Knowledge of the structure and composition of the solid phases of a soil is needed to understand the retention mechanisms of transition metals or organic pollutants on the molecular scale. With this aim, the characterization of a soil sample from the Champagne-Ardenne region was carried out using various non-destructive methods such as X-ray diffraction (XRD), transmission electron microscopy-energy dispersive X-ray spectrometry (TEM-EDX), Mössbauer and electron paramagnetic resonance (EPR) spectroscopies, X-ray photoelectron spectroscopy (XPS), and protometric studies. The combination of these techniques allowed us to obtain a precise knowledge of the solid structure and composition. We showed that soil particles consist of quartz, alumino-silicate and goethite which are partially covered by organic matter. XPS spectra showed that organic matter is preferentially coated onto an alumino-silicate surface. EPR spectroscopy revealed the presence of unexpected vanadyl moieties in the organic matter. Acid-base titrations provided information on available surface sites $\left(0.25 \mathrm{mmol} \times \mathrm{g}^{-1}\right.$, i.e. 2.25 sites per $\mathrm{nm}^{2}$ ), and the point of zero charge $\mathrm{pH}_{\mathrm{zpc}}$ (3.9).
\end{abstract}

soil / XRD / TEM-EDX / EPR / XPS / surface sites

\section{INTRODUCTION}

Adsorption and desorption processes at solid-liquid interfaces play a major role in environmental studies, especially in the control of the transport of metal cations and organic pollutants in surface and underground waters (Hochella, 1990). Therefore, an understanding of long-term pollutant availability depends on knowing the adsorption and desorption reactions taking place at the soil particle surfaces. In order to understand these processes a characterization of their structural and chemical properties is necessary. Adsorption of metals and organics, dissolution/precipitation reactions, and transport phenomena through pores occur at interfaces where physico-chemical properties are expected to be different from those of isolated soil components (clay, ferrous oxide, quartz, etc.). Advanced characterization tools are increasingly being used to study mineral-water interfaces, leading to major progress in the characterization of surface and interface structures and the nature of mineral dissolution, adsorption and growth. These include synchrotron radiation-based scattering and spectroscopy (Manceau et al., 2003; Nachtegaal and Sparks, 2003), vibrational spectroscopy (Mao et al., 2003), etc. Meanwhile, electrical properties, surface energetics, wetting properties, ionic diffusivities and thermodynamic properties of fluids near solid surfaces have also been investigated (Ellies et al., 2003).

With the aim of studying the retention of metal cations and organic pollutant retention in the Champagne-Ardenne region, we started a study in which the structural and chemical properties of the sorbent need to be carefully characterized. So, the main objectives of this work are to study the surface properties and the chemical composition of a soil sample, by using various physico-chemical techniques. A soil sample, representative of a typical site in the Champagne-Ardenne region located at the natural border between forest and vineyard, was chosen. It originates from a sedimentary basin essentially consisting of siliceous sand. The parcel where our sample came from has not undergone any treatment, so all of its components have a natural origin. These soil particles were then submitted to a thorough characterization of their structural and textural properties by combining various experimental approaches. We applied powder X-ray diffraction (XRD), transmission electron microscopy combined with energy dispersive X-ray spectrometry (TEM-EDX), X-ray photoelectron spectroscopy (XPS), Mössbauer and electron paramagnetic resonance (EPR) spectroscopies, protometric measurements, and electrophoresis analysis.

* Corresponding author: emmanuel.guillon@univ-reims.fr 


\section{MATERIALS AND METHODS}

Potassium nitrate $\left(\mathrm{KNO}_{3}\right)$, acids $\left(\mathrm{HNO}_{3}\right.$ and $\left.\mathrm{HCl}\right)$ and bases $(\mathrm{KOH}$ and $\mathrm{NaOH})$ were purchased from Fluka. All chemicals from commercial sources were analytical grade and were used without further purification.

\subsection{Soil sample extraction}

The soil from which the sample was taken is in the Champagne-Ardenne region (France). The detailed procedure of soil particle extraction has been described by Grasset and Amblès (1998). Briefly, the soil was dried at room temperature (RT) and sieved at $<100 \mu \mathrm{m}$. Extraction took place at RT for $24 \mathrm{~h}$ with chloroform (10 $\mathrm{mL}$ per gram) essentially to extract free lipids. After filtration, the residue was successively mixed for 12 hours with a $0.1 \mathrm{~mol} \mathrm{~L}^{-1} \mathrm{HCl}$ and $\mathrm{NaOH}$ solution $(10 \mathrm{~mL}$ per gram) to eliminate the most soluble fractions. After a new filtration and a water wash, the insoluble solid obtained was stirred in a nitric acid $\left(5 \times 10^{-2} \mathrm{~mol} \mathrm{~L}^{-1}\right)$ medium to saturate the proton surface sites. The solid was then water-washed and vacuumdried. These treatments allowed us to obtain an insoluble solid adsorbent, which is a necessary condition for further metallic cations and organic pollutants sorption experiments.

Elemental analyses in inorganic elements were performed by atomic emission spectrometry by inductive coupling plasma (ICP-AES), and in carbon, hydrogen and nitrogen by a thermal conductivity detector after fast calcination of the soil particles in air at the CNRS Service of Analysis (Vernaison, France).

A sample fraction was calcined up to $950{ }^{\circ} \mathrm{C}$ in $100 \mathrm{~mL} \mathrm{~min}^{-1}$ air flow and a heating rate of $5^{\circ} \mathrm{C} \mathrm{min}{ }^{-1}$, for further analysis. Combined differential thermal and thermogravimetric analyses (DTA/TGA) were obtained on a Seiko DT-TGA 320 module operated by a Seiko SSC5200 disk station. The flow rate of air was $100 \mathrm{~mL} \mathrm{~min}^{-1}$ and the heating rate $5{ }^{\circ} \mathrm{C} \mathrm{min}-1$. The production of gases during calcination was studied using a HPR20/ DSMS mass spectrometer. The pressure in the ionization chamber was $2.6 \times 10^{-4} \mathrm{~Pa}$.

\subsection{Electron microscopy}

Transmission electron microscopy (TEM) was performed on a $100 \mathrm{kV}$ JEOL 100 CXII UHR microscope. TEM - EDX analyses were obtained on a $200 \mathrm{kV}$ JEOL JEM 2010 microscope equipped with an X-ray emission spectrometer (PGT Imix PC system). The ground powder was dispersed in pure ethanol. The suspension was stirred in an ultrasonic bath and one drop was placed on a carbon-coated copper grid.

\subsection{X-ray diffraction}

Powder X-ray diffraction (XRD) was performed on a Siemens D500 diffractometer, using the Cu K $\alpha$ radiation (1.5418 $\AA$ ). The data collection was carried out from $2 \theta=5-70^{\circ}$ with a step of $0.02^{\circ}$ and an acquisition time of $10 \mathrm{~s}$. Diffraction data were analyzed by the Rietveld method, using the fully automated code RIETQUAN (Lutterotti et al., 1998), which is particularly useful for a quantitative evaluation of phases and reliable structural and microstructural information such as unit cell, average crystallite size and lattice strain.

\subsection{Mössbauer spectroscopy}

The ${ }^{57} \mathrm{Fe}$ Mössbauer spectra were measured at room temperature $(293 \mathrm{~K})$ and at liquid helium temperature $(4.2 \mathrm{~K})$ with both the ${ }^{57} \mathrm{Co} / \mathrm{Rh}$ source and the absorber at the same temperature at the "Physik-Department E15" of the "Technische Universität München". The spectrometer was operated with a sinusoidal velocity waveform and the spectra were fitted with superpositions of appropriate sets of Lorentzian lines using the MOS-90 computer program (Grosse, 1992). The magnetic hyperfine field $\mathrm{B}_{\mathrm{hf}}$, the electric quadrupole splitting $\mathrm{QS}$, the isomer shift IS (given relative to $\alpha-\mathrm{Fe}$ ), and the resonance area A in percent of the total iron are listed in Table III.

\subsection{Electron paramagnetic resonance}

Solid-state EPR spectra were obtained with a Brüker ELEXYS 500 spectrometer equipped with an Oxford Instruments helium-flow cryostat operating at X-band frequency with a 100-kHz modulation frequency. The spectra were recorded in the following conditions: microwave power $=10 \mathrm{~mW}$, modulation amplitude $=6 \mathrm{G}$. The spectra were carried out at different temperatures: $10 \mathrm{~K}, 80 \mathrm{~K}$, and at room temperature, $293 \mathrm{~K}$.

\subsection{X-ray photoelectron spectroscopy}

XPS data were collected using the facilities of the "Laboratoire de Chimie-Physique pour l'Environnement (LCPE)", located in Nancy, France. Measurements were performed on a VSW hemi-spherical spectrometer using a Mg K $\alpha(1235.6 \mathrm{eV})$ $\mathrm{X}$-ray source run at $150 \mathrm{~W}$. The X-ray gun was operated at $15 \mathrm{kV}$ and $10 \mathrm{~mA}$. The pressure in the sample analysis chamber was typically about $10^{-7} \mathrm{~Pa}$. Before measurements, the test chamber was first evacuated for $30 \mathrm{~min}$ to remove the residual moisture from the sample. All spectra were calibrated (to correct for the static charging effects) by using the "adventitious" $\mathrm{C} 1 \mathrm{~s}$ peak at $284.6 \mathrm{eV}$ (B.E.), which provided a consistent set of data with all compound peaks at their expected values. The overlapping peaks were resolved by the peak synthesis method, applying Shirley-type background subtraction. Spectra were measured on well-powdered samples with a thickness of about $1.0 \mathrm{~mm}$, placed in copper sample holders.

\subsection{Protometric procedure}

The total acidity content and the hydration time of soil particles were determined by potentiometric titrations as previously described (Guillon et al., 2001), at $293 \mathrm{~K}$ and at ionic strength equal to $0.1 \mathrm{~mol} \mathrm{~L}^{-1}$, in a potassium nitrate medium under a dynamic nitrogen atmosphere. The hydration time was determined by titration experiments of different suspensions containing the same powdered sample weight $(50 \mathrm{mg})$ immersed in $25 \mathrm{~mL}$ of $0.1 \mathrm{~mol} \mathrm{~L}^{-1} \mathrm{KNO}_{3}$ solution after several hydration times (30 min, $1 \mathrm{~h}, 4 \mathrm{~h}, 12 \mathrm{~h}, 24 \mathrm{~h}$ and $48 \mathrm{~h}$ ). Equilibration was considered to be reached when the titration curves were superimposed. The protometric measurements were carried out in a thermoregularized cell with a Metrohm $654 \mathrm{pH}$-meter equipped with a combined glass microelectrode Metrohm type $\mathrm{T}$ (low alkaline error), and a Dosimat 665 automatic burette (Metrohm) containing carbonate-free potassium hydroxide at $0.1 \mathrm{~mol} \mathrm{~L}^{-1}$. 
Table I. Elemental composition of the powder (wt \%).

\begin{tabular}{cc}
\hline $\mathrm{Si}$ & 32.6 \\
$\mathrm{Al}$ & 5.9 \\
$\mathrm{Fe}$ & 3.5 \\
$\mathrm{C}$ & 3.2 \\
$\mathrm{H}$ & 1.1 \\
$\mathrm{Ti}$ & 1.0 \\
$\mathrm{Na}$ & 0.9 \\
$\mathrm{~K}$ & 0.4 \\
$\mathrm{Ca}$ & 0.3 \\
$\mathrm{~N}$ & 0.2 \\
$\mathrm{Mg}$ & 0.1 \\
O (by difference) & 50.8 \\
\hline
\end{tabular}

\subsection{Zeta potential}

Experiments were performed using a Beckman-Coulter DELSA (Doppler Electrophoretic Light Scattering Analyzer) 440 SX, equipped with a photo diode array detector. The apparatus is equipped with a helium-neon laser and the detection was carried out at $632.8 \mathrm{~nm}$ and $298 \mathrm{~K}$. The zeta potential is obtained from the electrophoretic mobility through the Smoluchowski equation:

$$
\xi=(4 \pi \cdot \eta / \varepsilon) \cdot \mu
$$

\section{RESULTS AND DISCUSSION}

The combination of several physico-chemical and spectroscopic techniques was used to gain better knowledge of the structural and chemical properties of the soil sample. Each technique provides specific information, which correlated with the others allows us to obtain necessary data for further sorption experiments.

\subsection{Composition of the residue}

Elemental analyses showed that most of its content was mineral (Tab. I), with silicon as the major element, a significant quantity of aluminium, the presence of $\mathrm{C}, \mathrm{H}$ and $\mathrm{N}$, minor quantities of transition and alkali metals (the most abundant being iron) and traces of alkali-earth cations. Nitrate could not be detected by infrared spectroscopy on the powder. Thus, nitrogen was assigned to the organic fraction, since it is also a minor component of humic acids (Stevenson, 1992).

Calcination of the soil particles in air up to $950{ }^{\circ} \mathrm{C}$ caused a $10 \%$ weight loss, as evidenced by DT/TG analyses coupled with mass spectrometry. Four distinct phenomena occurred: (1) an endothermic loss of water at $60{ }^{\circ} \mathrm{C}$ (2 wt \% loss); $(2,3)$ two exothermic steps due to the calcination of the organic phase $\left(\mathrm{H}_{2} \mathrm{O}, \mathrm{CO}_{2}\right.$ and $\mathrm{NO}_{2}$ production, at 280 and $\left.380{ }^{\circ} \mathrm{C}\right)$, and (4) an endothermic step at $460{ }^{\circ} \mathrm{C}$, corresponding to dehydration. The second step corresponded to a $2.7 \mathrm{wt} \%$ loss and the third and fourth steps, which could not be distinguished by TGA, to a $5.3 \mathrm{wt} \%$ loss.
The dehydrated red mineral fraction remaining after calcination at $950{ }^{\circ} \mathrm{C}$ thus amounted to $90 \mathrm{wt} \%$ of the initial soil particles. In contrast with the total oxygen content (Tab. I), it was deduced that $5.5 \mathrm{O} \mathrm{wt} \%$ belong to the organic fraction.

\subsection{Qualitative structural analysis (TEM/EDX and XRD)}

These techniques are used to obtain information about the composition of the soil particles in terms of qualitative results. TEM/EDX of the initial soil particles showed four main types of mineral crystallites: (i) massive oblong crystallites (a few tenths $\mu \mathrm{m}$ ) of $\mathrm{SiO}_{2}$ (Si Ko peak at $1.74 \mathrm{keV}$ ) (Fig. 1a); (ii) various types of disordered aluminosilicate plates ( $\mathrm{Si} \mathrm{K} \alpha$ and $\mathrm{Al}$ $\mathrm{K} \alpha$ peaks at $1.49 \mathrm{keV}$ ), some of them containing traces of Fe, alkaline and alkaline earth metals (Fig. 1b); (iii) aggregates of iron oxides (predominant Fe K $\alpha$ peak at $6.40 \mathrm{keV}$ and $\mathrm{K} \beta$ peak at $7.06 \mathrm{keV}$ ), often in association with aluminosilicate plates (Fig. 1c), and (iv) $\mathrm{TiO}_{2}$ crystals ( $\mathrm{Ti} \mathrm{K} \alpha$ peak at $4.51 \mathrm{keV}$ and $\mathrm{K} \beta$ peak at $4.93 \mathrm{keV}$ ) (Fig. 1d).

XRD diffractograms (Fig. 2) of the initial soil particles (a), and those of the particles after calcination at $950{ }^{\circ} \mathrm{C}$ (b) show major peaks of $\alpha$-quartz $\mathrm{SiO}_{2}\left(\mathrm{Q}: 2 \theta=20.8,26.7,50.3,60.1^{\circ}\right.$, corresponding to $\mathrm{d}=4.26,3.34,1.81$ and $1.54 \AA$ (Brown and Brindley, 1984)), which is in line with elemental analyses and microscopy. The low-angle region of the diffractogram shows two diffraction lines attributed to layered aluminosilicates. A weak line $(\mathrm{M})$ at $2 \theta=8.9^{\circ}(\mathrm{d}=10.0 \AA)$, still present after calcination, is due to micas and illites. A more intense reflection found at $35.1^{\circ}(\mathrm{d}=2.56 \AA)$ confirms the presence of micas. Moreover, the broad diffraction halo at $2 \theta=7^{\circ}$ in Figure 2 a corresponds to the basal spacing of a disordered $\mathrm{Na}$-containing smectite $(\mathrm{d}=12.5 \AA)$ (Brown and Brindley, 1984). The peak at $12.4^{\circ}(\mathrm{K})$, attributed to the aluminosilicate plates, corresponds to the basal spacing of kaolinite $\mathrm{Si}_{2} \mathrm{Al}_{2} \mathrm{O}_{5}(\mathrm{OH})_{4}(\mathrm{~d}=$ $7.2 \AA$ ); other diffraction peaks can be found at $2 \theta=24.9$ (shoulder) and $38.7^{\circ}$ (respectively, $d=3.57$ and $2.33 \AA$ for $(002)$ and (20 $\overline{2}, 1 \overline{3} 1)$ reflections) (Bailey, 1984). These peaks disappear after calcination; the product of decomposition of kaolinite, metakaolinite, is often reported to be amorphous (Brindley and Lemaitre, 1987).

The broad diffraction peak at $33.3^{\circ}(\mathrm{d}=2.69 \AA)$ in Figure $2 \mathrm{a}$ (G) can originate from two phases of the iron-containing crystalline phase: goethite $\alpha-\mathrm{FeOOH}((130)$ reflection) or hematite $\mathrm{Fe}_{2} \mathrm{O}_{3}$ ((104) reflection) (Brown, 1984). Goethite is present in the initial soil particles and is dehydrated into hematite upon calcination (Fig. 2b, H). This transformation is the reason for the strong change in color of the solid, turning to bright red after heating (Velde, 1992).

Finally, the peak at $25.3^{\circ}$ is characteristic of $\mathrm{TiO}_{2}$ (anatase, A, $d=3.52 \AA,(101)$ reflection), often found in association with clays; that at $27.5^{\circ}$ is characteristic of rutile $(\mathrm{R}, \mathrm{d}=3.25 \AA,(110)$ reflection).

\subsection{EPR analysis}

An EPR analysis of the soil particles was done at 10, 80 and $293 \mathrm{~K}$ in order to characterize the different paramagnetic species present. Figure 3 a shows the EPR spectrum obtained at 
a)

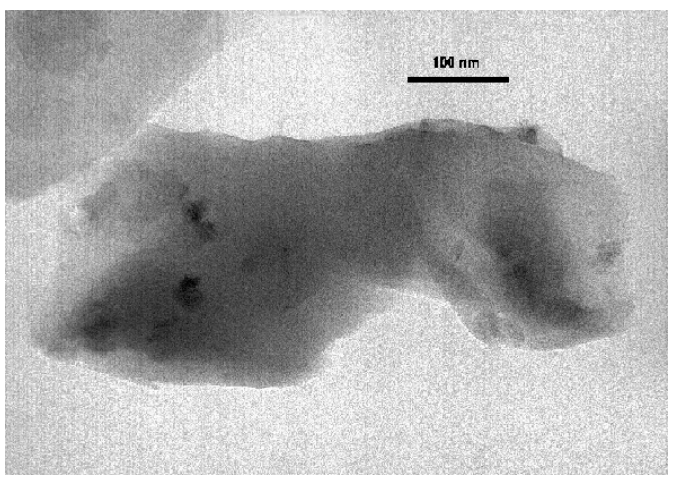

b)

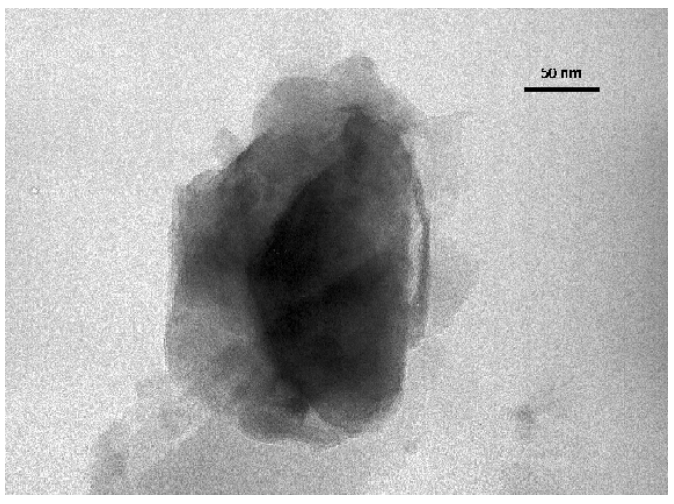

c)

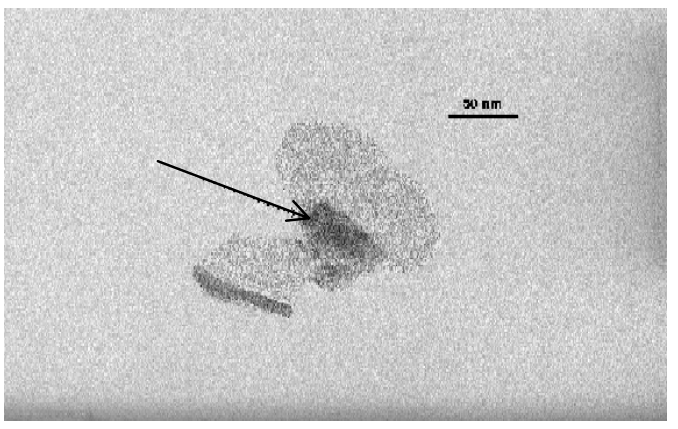

d)

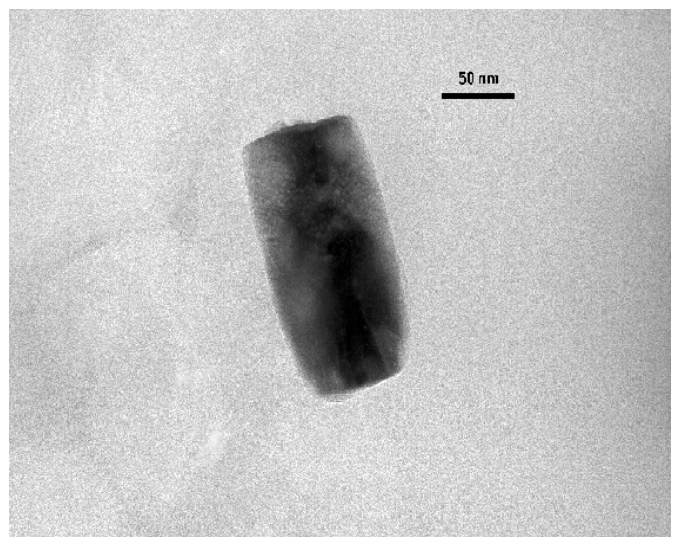

Figure 1. TEM micrographs of soil particles on which silicon dioxide grain (a), silicoaluminate plates (b), aggregates of oxidic iron compounds $(\rightarrow$ on a silicoaluminate plate $(\mathrm{c})$, and titanium dioxide grain (d) are shown.

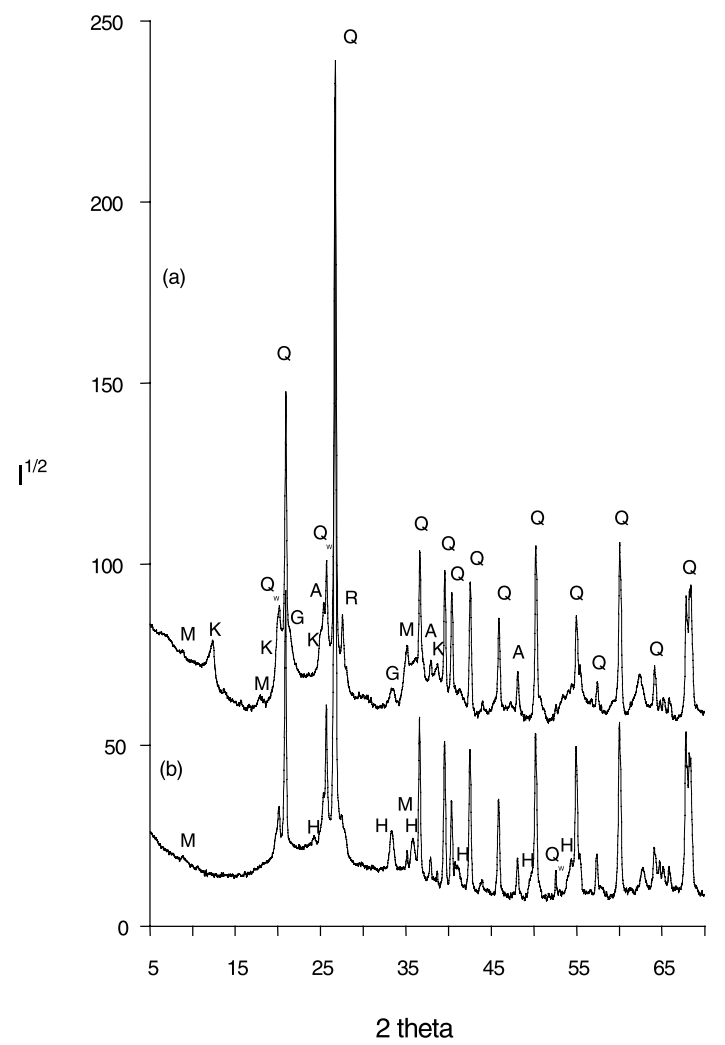

Figure 2. X-ray powder diffraction pattern of the initial (a) and after calcination at $950{ }^{\circ} \mathrm{C}(\mathrm{b})$ soil particles. $\mathrm{M}=$ illite/smectite; $\mathrm{K}=$ kaolinite; $\mathrm{Q}=$ quartz; $\mathrm{Q}_{\mathrm{W}}=$ diffraction of $\mathrm{W} \mathrm{K}$ radiation by quartz; $\mathrm{G}=$ goethite; $\mathrm{R}=$ rutile; $\mathrm{A}=$ anatase $\mathrm{H}=$ hematite.

$10 \mathrm{~K}$. This EPR spectrum is dominated by high spin $\mathrm{Fe}^{3+}$ contributions $\left(\mathrm{d}^{5}, \mathrm{~S}=5 / 2\right)$. The spin Hamiltonian of high spin $\mathrm{Fe}^{3+}$ includes the Zero Field Splitting (ZFS) interaction, characterized by the $D$ and $E$ tensors, as well as the electron Zeeman interaction characterized by the $g$ and $A$ parameters.

$$
H=g \beta \vec{B} \vec{S}+S[D] S .
$$

In this case, the $\mathrm{g}$ factor is isotropic and the EPR spectral characteristics are determined by the ZFS. Scaling factors of ZFS terms lead to the determination of the two parameters $D$ and $E$ which correspond to the following Hamiltonian:

$$
H=g \beta \vec{B} \vec{S}+D\left[S_{z}^{2}-\frac{1}{3}(S(S+1))\right]+E\left(S_{x}^{2}-S_{y}^{2}\right)
$$

The ZFS parameters, D and E, are a measure of the deviation of the ion crystal field from ideal tetrahedral or octahedral symmetries for which both $D=0$ and $E=0$. When the reduced symmetry is axial, $D \neq 0$ and $E=0$, while non-axial symmetry results in $D \neq 0, E \neq 0$. In the limit of rhombic symmetry, $E / D=1 / 3$.

We can distinguish at least two types of iron signal in the soil sample: (i) some rhombic iron for which $E / D \approx 1 / 3, D \approx$ $3 \mathrm{~cm}^{-1}$ with an isotropic signal at $\mathrm{g}=4.3$, originating from the middle Kramers doublet, and a broad feature at $g=9$ due to the 


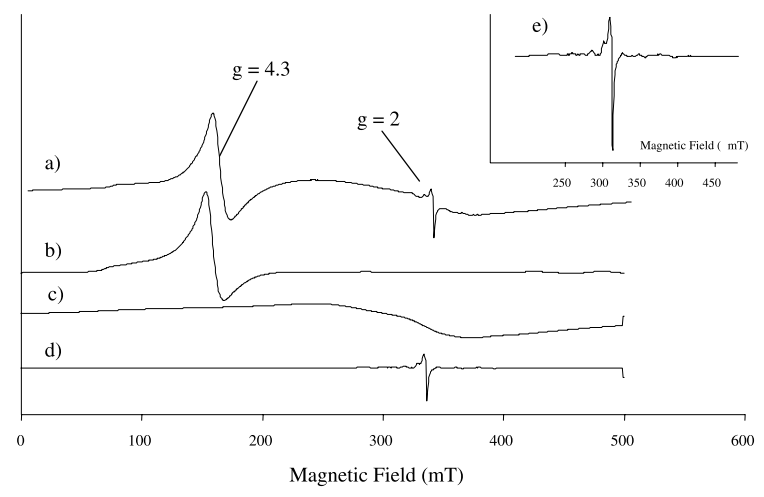

Figure 3. EPR spectra at $10 \mathrm{~K}$ of soil particles (a), rhombic iron contribution (b), nearly octahedral iron contribution (c), and vanadyl contribution (d) with an enlargement of the $350 \mathrm{mT}$ region (e). Spectra b, c, and d are obtained after subtraction of all the other contributions.

lowest Kramers doublet (Fig. 3b), and (ii) some nearly octahedral iron(III) sites giving a resonance at $\mathrm{g}=2.1$ in non-distorted sites occupying oxy or hydroxy species with $E \sim 0$ and $D \sim$ $0 \mathrm{~cm}^{-1}$ (Fig. 3c). The first type originates from trivalent iron in illite/smectite or kaolinite (Gehring and Karthein, 1990), the second one originates from goethite (Gehring and Hofmeister, 1994). Moreover, $\mathrm{Fe}^{3+}$ ions in exchangeable octahedral sites, with $E=0$ and $D=0$, were expected at $\mathrm{g}=2$ in such a sample. This contribution is not present here, probably due to the acidobasic treatment.

Another signal appears around $g=2$ (Figs. 3d, e). This signal could be characteristic of a vanadyl porphyrin (Hodgson et al., 1968 ) with an axial $g$ tensor from a $S=1 / 2$ with a hyperfine coupling to an axial $A$ tensor. We can then determine $g_{/ /}$coupled with an $A_{/ /}$, and $g_{\perp}$ coupled to $A_{\perp}$, arising from a $S=1 / 2$ coupled to a $I=7 / 2$ nucleus. This situation is described by the following Hamiltonian:

$$
H=g \beta \vec{B} \vec{S}+S[A] I
$$

This signal is characteristic of a V(IV)-containing porphyrin where the tensor $A$ is of the following type:

$$
H=\left[\begin{array}{ccc}
1.96 & 0 & 0 \\
0 & 1.96 & 0 \\
0 & 0 & 1.95
\end{array}\right] \beta \vec{B} \vec{S}+S\left[\begin{array}{ccc}
48 & 0 & 0 \\
0 & 52 & 0 \\
0 & 0 & 163
\end{array}\right] I
$$

These Hamiltonian parameters are also close to those found for vanadium(IV) ions into a matrix of titanium $\left(\mathrm{TiO}_{2}\right)$ (Davidson and Che, 1992). Vanadyl ions' $\left(\mathrm{VO}^{2+}\right)$ quantity, which have been previously shown by EPR spectroscopy in soil samples (Senesi et al., 1989), have been estimated at about $10 \mathrm{ppm}$.

\subsection{Repartition of the iron ions (Mössbauer spectroscopy)}

A Mössbauer study was carried out in order to quantify the iron species present in oxide/oxyhydroxide particles or in aluminosilicates. Figure 4 shows the Mössbauer spectra taken at

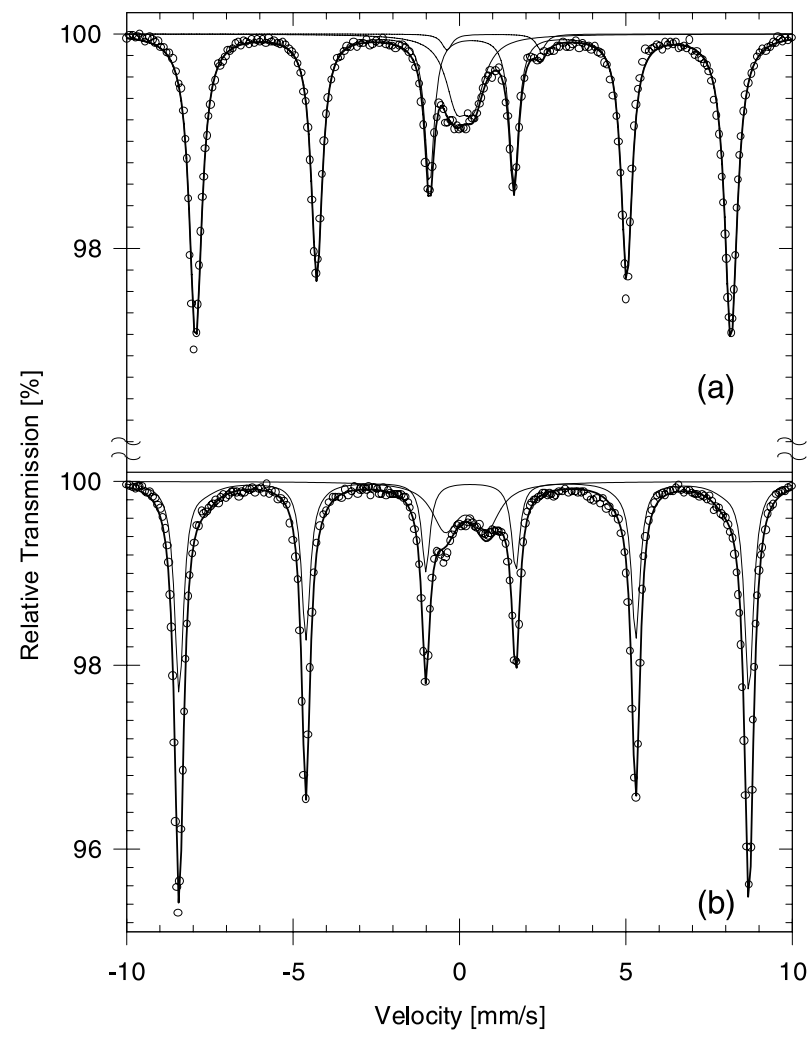

Figure 4. ${ }^{57} \mathrm{Fe}$ Mössbauer spectra at liquid helium temperature $(4.2 \mathrm{~K})$ of the initial soil particles (a) and of the same sample after calcination at $950{ }^{\circ} \mathrm{C}(\mathrm{b})$.

4.2 $\mathrm{K}$ before and after calcination. Both spectra show a six-line magnetic pattern, typical of iron oxides or oxyhydroxides, and two weak quadrupole doublets typical of divalent and trivalent paramagnetic $\mathrm{Fe}$, respectively.

In the case of the initial soil particles, the hyperfine parameters of the magnetic sextet at $4.2 \mathrm{~K}$ (Tab. II) are attributed to goethite. The hyperfine field $(49.9 \mathrm{~T})$ is slightly lower than the expected value of $50.65 \mathrm{~T}$. A lower value can be due to Al-substitution or poor crystallinity (Murad and Johnston, 1987). No significant $\mathrm{Al}$ was noticed in the EDX spectra of the iron-rich zones. Using the relation (Murad and Schertmann, 1983):

$$
\left[\mathrm{B}_{\mathrm{hf}}\right]^{4.2 \mathrm{~K}}=50.65-8.7 /(\text { mean crystal diameter })_{111}
$$

we can estimate the crystalline domain size of goethite in its aggregates as about $12 \mathrm{~nm}$, in line with TEM results and with the lack of magnetic order in the spectrum at room temperature, which indicates that the particles of goethite have a size smaller than $15 \mathrm{~nm}$.

After calcination, the hyperfine parameters of the magnetic sextet correspond to hematite (Tab. II), also identified by X-ray diffraction. Hematite does not undergo the Morin transition even at $4.2 \mathrm{~K}$ and is present in the weakly ferromagnetic form (QS $=-0.20 \mathrm{~mm} / \mathrm{s}, \mathrm{IS}=0.35 \mathrm{~mm} / \mathrm{s})$, which shows that it is not particularly well crystallized (particle size smaller than $20 \mathrm{~nm}$ ) 
Table II. Mössbauer parameters at room temperature and at liquid helium temperature for the pure and the calcined residue samples.

\begin{tabular}{|c|c|c|c|c|c|c|c|}
\hline SAMPLE & $\begin{array}{c}\text { Temp. } \\
{[\mathrm{K}]}\end{array}$ & $\begin{array}{l}\text { Bhf } \\
{[\mathrm{T}]}\end{array}$ & $\begin{array}{c}\mathrm{QS} \\
{[\mathrm{mm} / \mathrm{s}]}\end{array}$ & $\begin{array}{c}\mathrm{IS} \\
{[\mathrm{mm} / \mathrm{s}]}\end{array}$ & $\begin{array}{c}\mathrm{LW} \\
{[\mathrm{mm} / \mathrm{s}]}\end{array}$ & $\stackrel{\mathrm{A}}{\mathrm{A}}$ & Iron Site \\
\hline \multirow[t]{5}{*}{ Pure residue } & 293 & - & $2.64(6)$ & $1.17(3)$ & $0.33(5)$ & $3(2)$ & $\mathrm{Fe}^{2+}$ in silicates \\
\hline & & - & $0.59(1)$ & $0.36(1)$ & $0.45(1)$ & $97(2)$ & Total $\mathrm{Fe}^{3+}$ \\
\hline & 4.2 & $49.9(1)$ & $-0.25(1)$ & $0.35(2)$ & $0.45(1)$ & $85(1)$ & Goethite \\
\hline & & - & $2.85(5)$ & $1.15(2)$ & $0.36(5)$ & $2(1)$ & $\mathrm{Fe}^{2+}$ in silicates \\
\hline & & - & $0.52(2)$ & $0.27(1)$ & $0.76(3)$ & $13(1)$ & $\mathrm{Fe}^{3+}$ in silicates \\
\hline Calcined residue & 293 & 51.3(1) & $-0.22(1)$ & $0.37(1)$ & $0.60(3)$ & $79(1)$ & Hematite \\
\hline \multirow[t]{4}{*}{$\left(950^{\circ} \mathrm{C}\right)$} & & - & $0.60(2)$ & $0.35(1)$ & $0.35(3)$ & $7(1)$ & Superparamagnetic hematite \\
\hline & & - & $1.32(5)$ & $0.31(1)$ & $0.83(4)$ & $14(1)$ & $\mathrm{Fe}^{3+}$ in silicates \\
\hline & 4.2 & $53.1(1)$ & $-0.20(1)$ & $0.35(1)$ & $0.33(1)$ & $88(1)$ & Hematite \\
\hline & & - & $1.24(2)$ & $0.30(1)$ & $0.90(6)$ & $12(1)$ & $\mathrm{Fe}^{3+}$ in silicates \\
\hline
\end{tabular}

(Murad and Johnston, 1987). However, the presence of superparamagnetic relaxation only for a small fraction of the hematite at room temperature, causing a partial collapse of the sixline pattern into a simple Fe(III) quadrupole doublet, puts a lower limit on the size of most of the hematite particles, which must be thus preponderantly larger than $8 \mathrm{~nm}$ and probably result from the dehydration of 12-nm goethite particles (Murad and Johnston, 1987).

In addition to the magnetic sextet observed at $4.2 \mathrm{~K}$ on the initial soil particles, two minor quadrupole doublets (Tab. II) have hyperfine parameters in the range of $\mathrm{Fe}(\mathrm{II})$ and $\mathrm{Fe}(\mathrm{III})$ in silicates, respectively, amounting to $15 \%$ of the total iron ions. $\mathrm{The} \mathrm{Fe}(\mathrm{II})$ doublet probably represents divalent iron in micalike structures: in fact, its QS value is halfway between that observed for cis- and trans-Fe ${ }^{2+}$ octahedral sites in muscovite (Shabani et al., 1998). Given the fact that iron in aluminosilicates is always associated in EDX with alkaline ions, we will assume that these $\mathrm{Fe}^{2+}$ and $\mathrm{Fe}^{3+}$ species belong mainly to the illite/smectite fraction.

\subsection{Quantitative analysis}

From the results of elemental analyses, and Mössbauer and EPR spectroscopies, a quantitative assessment of the different phases present in the initial soil particles can be proposed. In this calculation, the illite/smectite formula is supposed to derive from muscovite: $\mathrm{M}\left(\mathrm{Al}_{2}\right)\left[\mathrm{Si}_{3} \mathrm{AlO}_{10}(\mathrm{OH})_{2}\right] \cdot \mathrm{xH}_{2} \mathrm{O}$, where $\mathrm{M}$ corresponds to sodium, potassium and calcium ions as interlayer cations; $\mathrm{Fe}^{3+}$ substitutes $\mathrm{Al}^{3+}$ in the octahedral position; $\mathrm{Fe}^{2+}$ and $\mathrm{Mg}^{2+}$ substitute $\mathrm{Al}^{3+}$ in the octahedral position, while $\mathrm{Si}(\mathrm{IV})$ substitutes $\mathrm{Al}^{3+}$ in the tetrahedral position. The quantity of interlayer water is supposed to be $2 \%$ of the total weight, as observed by TGA. The proportions of the other components of the mineral fraction are given in Table III.

Another mode of quantitative analysis on the mineral fraction was carried out by Rietveld analysis of the initial powder XRD pattern (Fig. not shown). The quantitative analysis of the crystalline phases resulting from the refinement is summarized in Table 3. A comparison with the quantification obtained from elemental analyses shows that illite/smectite is underestimated by Rietveld analysis, whereas kaolinite and $\mathrm{TiO}_{2}$ are overesti- mated. The crystallinity of $\mathrm{TiO}_{2}$ and kaolinite explains their overestimation compared with disordered illite/smectite particles. It is also possible that illite/smectite was overestimated by elemental analyses quantification, due to the uncertainty on its exact formula.

In conclusion, the mineral fraction of the powder contains about $65 \mathrm{wt} \%$ of silicon dioxide, most of which is present as quartz; $28 \mathrm{wt} \%$ of clay mineral particles, illite/smectite and kaolinite, probably in a $2 / 1$ ratio; $5 \mathrm{wt} \%$ of goethite; $2 \mathrm{wt} \%$ of titanium dioxide, as rutile and anatase in a $3 / 2$ ratio.

\subsection{Surface chemical composition by XPS}

Prior to the XPS surface study, the specific surface area of the soil particles $\left(33.5 \mathrm{~m}^{2} \mathrm{~g}^{-1}\right)$ was determined from a nitrogen adsorption isotherm using the BET method (Monosorb Quantachrome). This value is relatively high compared with the ones obtained with kaolinite-humic acid complex $\left(13 \mathrm{~m}^{2} \mathrm{~g}^{-1}\right.$ ) (Nachtegaal and Sparks, 2003), or other soil samples $\left(20.8 \mathrm{~m}^{2} \mathrm{~g}^{-1}\right)$ from Pakistan (Riaz et al., 1996).

Soil particles were analyzed by XPS to determine their surface chemical composition. This technique gives an overall view of the species which contribute to the surface, contrary to EDX which is a local probe. Indeed, XPS is a surface-specific method which probes the chemical composition of the uppermost 2-10-nm-thick surface layer. This layer is especially interesting because of its implication in the surface complex formation. Table IV presents the surface chemical composition

Table III. Quantitative analysis of the mineral phases, from elemental analyses and from the Rietveld refinement of the XRD data of the mineral fraction $(\Sigma$ weight fractions $=100 \%)$.

\begin{tabular}{lcc}
\hline Mineral Phase & $\begin{array}{c}(\mathrm{wt} \%) \\
\text { [Elemental analyses] }\end{array}$ & $\begin{array}{c}(\mathrm{wt} \%) \\
\text { [Rietveld] }\end{array}$ \\
\hline Quartz & 60 & 67 \\
Illite/Smectite & 27 & 7 \\
Kaolinite & 6 & 15 \\
Goethite & 5 & 6 \\
Rutile/Anatase & 2 & $5(3 / 2)$ \\
\hline
\end{tabular}


Table IV. Surface chemical composition determined by XPS (wt \%).

\begin{tabular}{cc}
\hline $\mathrm{O}$ & 61.1 \\
$\mathrm{C}$ & 16.2 \\
$\mathrm{Si}$ & 13.3 \\
$\mathrm{Al}$ & 9.0 \\
$\mathrm{Fe}$ & 0.2 \\
$\mathrm{~K}$ & $0.06^{\mathrm{a}}$ \\
$\mathrm{Ca}$ & $0.04^{\mathrm{a}}$ \\
$\mathrm{Ti}$ & $0.02^{\mathrm{a}}$ \\
\hline
\end{tabular}

${ }^{\mathrm{a}}$ Detection limit (traces).

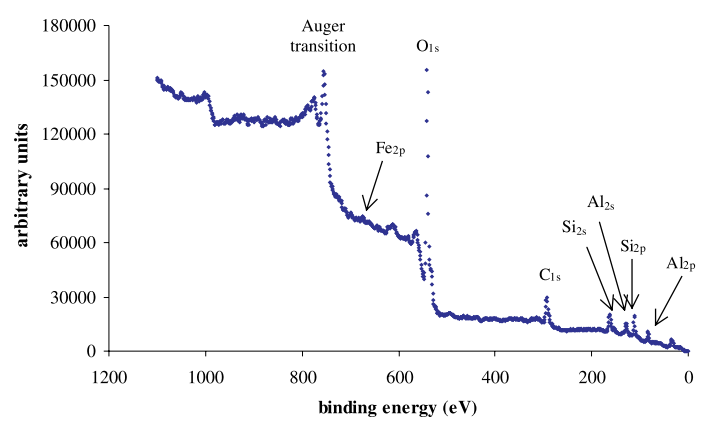

Figure 5. XPS survey spectrum of the soil particles showing the main surface constituents.

of the sample obtained from the survey spectrum (Fig. 5). The titanium contribution, obtained by XPS, from the $\mathrm{TiO}_{2}$ fraction is negligible at the surface, which indicates that $\mathrm{TiO}_{2}$ do not contribute to the specific surface area. This is in accordance with the bulky rectangular crystallites observed by TEM/EDX. The carbon concentration was used as an indication of the organic content of the analyzed surface layer. The high carbon concentration, as compared with bulk composition (Tab. I), can be explained by the surface sensitivity of the technique and the surface localization of the organic matter. This is in agreement with most of the organic matter coated on the inorganic surface (quartz, clay, and goethite essentially) as previously shown for the kaolinite-humic acid complex (Nachtegaal and Sparks, 2003), or other soil particles (Gerin and Dufrêne, 2003). Si and $\mathrm{Al}$ are the major elements detected at the surface. Si was the predominant mineral element detected, in line with the expected quartz and aluminosilicate presence. The higher content of $\mathrm{Al}$ at the surface than in the bulk solid (Si/Al atomic ratio $=1.5$ instead of 5.3 in the bulk) suggests that the organic matter is linked to the aluminosilicate (illite, smectite and kaolinite) fraction. Fe was detected in very low quantity at the surface, while a significant amount was measured in the solid (Tab. I). This could be consistent with the presence of a layer of organic material adsorbed on the ferric oxide particles, this organic layer being thick enough to mask the Fe atoms for the XPS analysis (Oades, 1989). Comparison of the relative concentrations of $\mathrm{Si}, \mathrm{Al}$ and $\mathrm{Fe}$ at the surface of the soil particles shows that organic matter has an increasing affinity for adsorption on the mineral surfaces in the order aluminosilicate, ferric oxide, and quartz, which is also in line with the known prop- erties of these soil constituents (Gerin and Dufrêne, 2003; Oades, 1989). This great affinity of organic matter for the aluminosilicate fraction is also supported by the $\mathrm{Si} / \mathrm{Al}$ ratio obtained by XPS (1.5), which excludes the quartz fraction. This allows us to conclude that clay and ferric oxide fractions mainly contribute to the specific surface area.

An accurate analysis of the XPS spectrum in the range 510$540 \mathrm{eV}$ reveals the presence, in very low intensity, of the two $\mathrm{V}_{2 p}$ satellite peaks near the $\mathrm{O}_{1 \mathrm{~s}}$ one. The $\mathrm{V}_{2 \mathrm{p}}$ spectrum consists of a major $V_{2 p 3 / 2}$ peak at a binding energy of $527 \mathrm{eV}$, spin orbit splitting by $\sim 5 \mathrm{eV}$ from the $\mathrm{V}_{2 \mathrm{p} 1 / 2}$ component of the doublet $(522 \mathrm{eV})$. This result confirms the EPR spectrum of the soil sample at $10 \mathrm{~K}$ (Fig. 3d) which exhibits, after subtraction of ferric oxide, a typical seven-lines feature of vanadyl ion with $S=$ $1 / 2$ and $I=7 / 2$. The Hamiltonian parameters obtained by EPR and the XPS results are in accordance with the presence of vanadium(IV) moieties in the organic matter fraction rather than in $\mathrm{TiO}_{2}$. Indeed, titanium, present in higher quantity than vanadium in the bulk, is detected in very small quantity only by XPS. So, vanadium species are essentially present at the surface of the soil particles, coating the organic matter.

In the case of the $C_{1 s}$ peak, a high resolution deconvoluted spectrum was carried out. The deconvolution used Gaussian peak shapes and integrated background subtraction. The $\mathrm{C}-\mathrm{O}$ region is interesting because the oxygen-containing groups should be responsible for the binding of the metal ions (Merdy et al., 2002). The deconvolution gives three components: the first one $(70.3 \%)$ at $284.46 \mathrm{eV}$ corresponds to carbon atoms bound to carbon or hydrogen atoms (C-C, C-H), the second one $(22.0 \%)$ at $286.08 \mathrm{eV}$ corresponds to carbon atoms singly bound to oxygen atoms (C-O), and the last (7.7\%) at $287.68 \mathrm{eV}$ corresponds to carbon atoms doubly bound to oxygen atoms $(\mathrm{C}=\mathrm{O})$ attributed to carbonyl and carboxylic moieties. These values are characteristic of carbon atoms from lignin (Merdy et al., 2002) and/or humic substances (Monteil-Rivera et al., 2000), which are the main component of organic matter. Moreover, from the $\mathrm{C}_{1 \mathrm{~s}}$ and $\mathrm{O}_{1 \mathrm{~s}}$ high resolution deconvoluted spectra, the presence of carbonate can completely be ruled out.

\subsection{Solid-solution interface chemistry}

The experiments consisted of alkalimetric (with $\mathrm{KOH}$ $0.1 \mathrm{~mol} \times \mathrm{L}^{-1}$ ) and acidimetric (with $\mathrm{HNO}_{3} 0.1 \mathrm{~mol} \times \mathrm{L}^{-1}$ ) titrations of the background salt alone $\left(\mathrm{KNO}_{3} 0.1 \mathrm{~mol} \times \mathrm{L}^{-1}\right)$ and in the presence of the solid suspension (Fig. 6). The titration was carried out on the aged suspension by adding incremental volumes of titrant, with a delay time of $2 \mathrm{~min}$, in accordance with the $\mathrm{pH}$ equilibrium. First of all, we determined the time required to reach the equilibrium between the dried powdered solid and the aqueous medium (hydration time), which was found to be equal to 4 hours. Then, we determined the surface site concentration from saturation experiments. If we plot the mole number of $\mathrm{OH}^{-}$ions added to the suspension versus the mole number of $\mathrm{OH}^{-}$present in aqueous solution (related to the $\mathrm{pH}$ measurements), we obtain a curve with a slope similar to the one obtained by titrating the electrolyte without added solid. This indicates that saturation is achieved. In this case the amount of sorbed $\mathrm{OH}^{-}$is supposed to be equal to the total concentration of available surface sites $\left(\mathrm{T}_{\mathrm{SOH}}\right): 0.25 \mathrm{mmol} \times \mathrm{g}^{-1}$, 


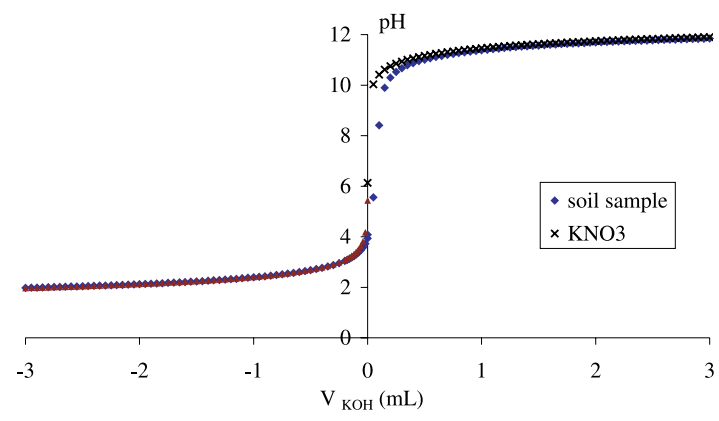

Figure 6. Acid-base titration of a $2 \mathrm{~g} \times \mathrm{L}^{-1}$ soil particle solution in $\mathrm{KNO}_{3} 0.1 \mathrm{~mol} \times \mathrm{L}^{-1}$ at $293{ }^{\circ} \mathrm{C}$.

which leads to a site density equal to 2.25 sites per $\mathrm{nm}^{2}$. It is also interesting to note that no amphoteric sites were observed.

The surface charge was determined by acid-base titrations, and the point of zero charge, $\mathrm{pH}_{\mathrm{zpc}}$, was found to be 3.9. This value is intermediate between quartz $\alpha-\mathrm{SiO}_{2}(2.0)$, kaolinite (4.7), and ferric oxide (6-8) particles (Sposito, 1984), in accordance with the different mineral phases which constitute our soil particles (Tab. III). Moreover, the isoelectric point, $\mathrm{pH}_{\mathrm{iep}}$, was obtained from the electrokinetic measurements, and was found to be 3.3, less than the $\mathrm{pH}_{\mathrm{zpc}}$. Similar results have been reported by other researchers (Subramaniam et al., 2001). Theoretically, one may expect that these two values, $\mathrm{pH}_{\mathrm{zpc}}$ and $\mathrm{pH}_{\mathrm{iep}}$, should be the same if only inert electrolytes are present; there may be sources of charge or potential such as ion exclusion or oriented water molecules between the surface and the shear plane that may cause a difference between these quantities (Parks, 1975). It is likely that this phenomenon may have been operative in our system. The $\mathrm{pH}$ of the soil is in the range $\sim 3-9$. Our $\mathrm{pH}_{\mathrm{zpc}}$ value indicates that the surface is negatively charged in this range, which allows us to expect a relatively good affinity and retention capacity of the soil particles towards metallic cations and organic pollutants.

\section{CONCLUSION}

Although the characterization of soil organic matter, clays or ferric oxides has been the subject of several studies, such information obtained directly on soil particles has been lacking until now. The procedure presented here, which consists of using several complementary physico-chemical methods, allows the characterization of a soil sample in terms of its chemical composition, crystal structure, morphology and acid-base properties. The combined use of DRX, TEM-EDX and Mössbauer for the characterization of soil particles revealed that they appeared as quartz particles mixed with aluminosilicate and goethite particles, these mineral surfaces being partially covered with adsorbed organic matter. A preferential adsorption of this latter on the aluminosilicate surface was underlined by the use of XPS. EPR experiments allowed us to reveal the presence of vanadyl ions in our sample. Acid-base titrations provide information concerning concentration of available surface sites, and the value of point of zero charge $\mathrm{pH}_{\mathrm{zpc}}$.
These data will be very useful for further study of this solid, especially concerning its properties at the solid-solution interface towards pollutants such as metallic cations or pesticides. Indeed, these data will be used to characterize how environmentally important pollutants are sequestered in soils on the molecular scale, which is critical to developing a solid scientific basis for maintaining soil quality and formulating effective remediation strategies.

Acknowledgements: The authors thank Dr. Hélène Suquet (Laboratoire de Réactivité de Surface, Paris) for her helpful comments on the chemistry of clay minerals, and Prof. F.E. Wagner (Physik-Department E15, Technische Universität München) for carrying out the Mössbauer experiments. The authors also gratefully acknowledge Dr. J. Lambert (LCPE, Université de Nancy I) for the XPS measurements.

\section{REFERENCES}

Bailey S.W. (1984) Crystal Structures of Clay Minerals and their X-Ray Identification, in: Brindley G.W., Brown G. (Eds.), Mineralogical Society, London, 2nd ed., pp. 1-124.

Brindley G.W., Lemaitre J. (1987) Chemistry of Clays and Clay Minerals, in: Newman A.C.D. (Ed.), Wiley, London, 1st ed., pp. 319370 .

Brown G. (1984) Crystal Structures of Clay Minerals and their X-Ray Identification, in: Brindley G.W., Brown G. (Eds.), Mineralogical Society, London, 2nd ed., pp. 361-410.

Brown G., Brindley G.W. (1984) Crystal Structures of Clay Minerals and their X-Ray Identification, in: Brindley G.W., Brown G. (Eds.), Mineralogical Society, London, 2nd ed., pp. 305-360.

Davidson A., Che M. (1992) Temperature-induced diffusion of probe vanadium (IV) ions into the matrix of tituanium dioxide as investigated by ESR techniques, J. Chem. Phys. B 96, 9909-9915.

Ellies A., Hartge H., MacDonald R., Ramirez C. (2003) Organic matter and wetting properties of soil samples - an interpretation, J. Plant Nutr. Soil Sci. 166, 120-123.

Gehring A.U., Karthein R. (1990) An ESR and calorimetric study of iron oolitic samples from the Nothampton Ironstone, Clay Min. 25, 303-311.

Gehring A.U., Hofmeister A.M. (1994) The transformation of lepidocrocite during heating: a magnetic and spectroscopic study, Clay Min. 42, 409-415.

Gerin P.A., Dufrêne Y.F. (2003) Native surface structure of natural soil particles determined by combining atomic force microscopy and X-ray photoelectron spectroscopy, Coll. Surf. B: Biointerfaces 28, 295-305.

Grasset L., Amblès A. (1998) Structure of humin and humic acid from an acid soil as revealed by phase transfer catalyzed hydrolysis, Org. Geochem. 29, 881-891.

Grosse G. (1992) Mos90 (Version 2.2), Technical University of Munich.

Guillon E., Merdy P., Aplincourt M., Dumonceau J., Vezin H. (2001) Structural characterization and iron(III) binding ability of dimeric and polymeric lignin models, J. Colloid Interface Sci. 239, 39-48.

Hochella M.F. (1990) Mineral-Water Interface Geochemistry, in: Hochella M.F. Jr., White A.F. (Eds.), Mineralogical Society of America, Washington DC, Vol. 23, pp. 87-132.

Hodgson G.W., Hitchon B., Taguchi K., Baker B.L., Peake E. (1968) Geochemistry of porphyrins, chlorines, and polycyclic aromatics in soils, sediments, and sedimentary rocks, Geochim. Cosmochim. Acta $32,737-772$. 
Lutterotti L., Ceccato R., Dal Maschio R., Pagani R. (1998) Quantitative analysis of silicate glass in ceramic materials by the Rietveld method, ed. Materials Science Forum, pp. 278-281 (Pt. 1, Proceedings of the fifth European Powder Diffraction Conference, 1997).

Manceau A., Tamura N., Celestre R.S., MacDowell A.A., Geoffroy N., Sposito G., Padmore H.A. (2003) Molecular-scale speciation of Zn and $\mathrm{Ni}$ in soil ferromanganese nodules from Loess soils of the Mississippi basin, Environ. Sci. Technol. 37, 75-80.

Mao J.D., Hundal L.S., Schmidt-Rohr K., Thompson M.L. (2003) Nuclear magnetic resonance and diffuse-reflectance infrared Fourier transform spectroscopy of biosolids-derived biocolloidal organic matter, Environ. Sci. Technol. 37, 1751-1757.

Merdy P., Guillon E., Dumonceau J., Aplincourt M. (2002) Characterisation of a wheat straw cell wall residue by various techniques, A comparative study with a synthetic and an extracted lignin, Anal. Chim. Acta 459, 133-142.

Monteil-Rivera F., Brouwer E.B., Masset S., Deslandes Y., Dumonceau J. (2000) Combination of X-ray photoelectron and solid-state ${ }^{13} \mathrm{C}$ nuclear magnetic resonance spectroscopy in the structural characterisation of humic acids, Anal. Chim. Acta 424, 243-255.

Murad E., Schwertmann U. (1983) The influence of aluminum substitution and crystallinity on the Mössbauer spectra of goethite, Clay Min. 18, 301-312.

Murad E., Johnston J.H. (1987) Mössbauer Spectroscopy Applied to Inorganic Chemistry, in: Long G.J. (Ed.), Plenum Press, New York, Vol. 2, pp. 507-582.
Nachtegaal M., Sparks D.L. (2003) Nickel sequestration in a kaolinitehumic acid complex, Environ. Sci. Technol. 37, 529-534.

Oades J.M. (1989) Minerals in soil environments, Soil Science Society of America Inc.

Parks G.A. (1975) Chemical oceanography, in: Riley J.P., Skirrow G. (Eds.), Academic Press, New York.

Riaz Q., Rizwan H., Sabir C.M., Saleem M. (1996) Characterization of Ludwa soil, J. Chem. Soc. Pakistan 18, 60-63.

Shabani A.A.T., Rancourt D.G., Lalonde A.E. (1998) Determination of cis and trans $\mathrm{Fe}^{2+}$ populations in $2 \mathrm{M} 1$ muscovite by Mossbauer spectroscopy, Hyperfine Interact. 117, 117-129.

Senesi N., Sposito G., Holtzclaw K.M., Bradford G.R. (1989) Chemical properties of metal-humic acid fractions of a sewage sludgeamended Aridisol, J. Environ. Qual. 18, 186-194.

Sposito G. (1984) The electrified interface in soils, in: The surface chemistry of soils, Oxford University Press, New York, pp. 78-112.

Stevenson F.J. (1992) Reactive functional groups of humic substances, in: Humus chemistry: genesis, composition, reactions, Wiley, New York, pp. 221-243.

Subramaniam K., Yiacoumi S., Tsouris C. (2001) Copper uptake by inorganic particles - equilibrium, kinetics, and particle interactions: experimental, Colloids Surfaces A 177, 133-146.

Velde B. (1992) Introduction to Clay Minerals, Chapman and Hall, London, 1st ed., pp. 69-99.

To access this journal online: www.edpsciences.org 